\title{
Christian Darras, consultor de la OPS "He crecido en contacto con los especialistas chilenos"
}

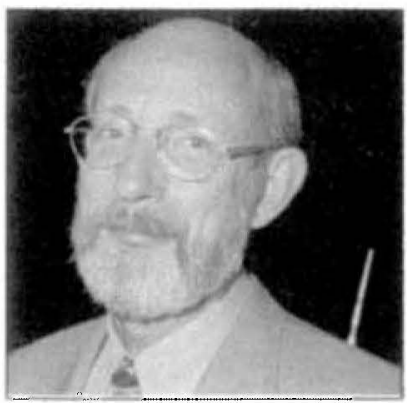

Christian Darras tiene 57 años y una estampa digna del mejor grabado del Quijote. Es de nacionalidad belga, pero nació y se crió en el Congo; médico especialista en Salud Pública, fue consultor de la OPS en Chile hasta el verano del 2005. Después de cinco años, marcha a Bolivia, para cumplir similar rol y para reencontrarse con dos hijos y un nieto que viven en Santa Cruz. Antes de tomar el avión, Darras compartió unas últimas palabras, en un acento marcadamente francés, sobre su vida, la recientemente aprobada Reforma de Salud y los recuerdos que se lleva.

\section{- ¿Así que es de nacionalidad belga pero de corazón africano?}

-Nací en África, en lo que ahora es el Congo y que ha vuelto a llamarse República Democrática del Congo. Pero mis dos padres son belgas, por eso mi nacionalidad es belga. Después volví a Bélgica.

Yo naci allá porque mi padre trabajaba en el Congo y me quedé más o menos hasta los 20 años. Empecé la universidad allá también.

\section{-iMedicina?}

Hice 2 años de medicina en el Congo y después volví a Bélgica para terminar la carrera. Luego, retorné al Congo a trabajar por cinco años más, como médico, equivalente a un "general de zona". Luego, volví a Bélgica para hacer mi maestría en salud pública y trabajé casi 2 años como asistente en la Escuela de Salud Pública de Bélgica. Después, el lnstituto me propuso un trabajo en Bolivia, había un proyecto de la cooperación belga en la parte baja, en la parte tropical, donde la población estaba llegando en grandes cantidades y tenía que enfrentar el problema de las enfermedades tropicales. Eso fue en 1981. Después pasé a otro proyecto de la cooperación belga para la organización del servicio de salud en la parte rural del departamento de Santa Cruz. Después, me enviaron a La Paz para trabajar en la representación de la OMS.

-Tengo entendido que su padre es médico ¿El gen de la medicina es fuerte en su familia?

-Parece (risas). Ya son tres generaciones, mi padre yo y mis hijos, y después mi madre era enfermera, una hermana enfermera también y su hija también en la salud. La salud tiene un componente fuerte en mi familia.

\section{- ¿Cuánto tiempo estuvo en Bolivia?}

-En Santa Cruz me quedé 12 años, hasta 1993. Después, seguí en La Paz como jefe del sector salud de la corporación belga de La Paz, que cubría los países latinoamericanos, principalmente Bolivia, Perú y Ecuador. En total, en Bolivia estuve 18 años, hasta 1999. En ese momento, hubo una reforma de la corporación belga y yo preferí salir. Así que postulé al cargo aquí en Chile, en Santiago, y felizmente fui elegido. Llegue en el 2000 y van a hacer 5 años.

\section{$-i$ Y por qué regresó a Bolivia?}

- En este tipo de organización siempre se va cambiando de plaza, después de 4 ó 5 años. Además, me ofrecieron volver a Bolivia como representante de la OMS, ya no como la cooperación belga. 
-18 años en Bolivia, 5 años acá ¿Cómo es el panorama de la medicina en Sudamérica? ¿Hay muchas similitudes o diferencias?

- Sí, obviamente hay similitudes y diferencias. En América Latina, generalmente, el financiamiento del Estado viene por intermedio de la misma organización de los servicios de salud; digamos, la tradición americana ha sido que el Estado construya y apueste directamente a los servicios con un acceso gratuito universal o barato pero con una organización estatal. Esa es la característica general $y$, al lado de eso, un sector privado que se desarrolla paralelamente sin mecanismos de solidaridad entre lo dos sistemas. En muchos países, no es el caso de Chile, hay un tercer sector que es el de la seguridad social basada en el sistema de cajas. En eso, Chile es un poco diferente, no tiene sistema de cajas, la seguridad social es para todo el mundo pero también tiene un sector privado y uno público. Otra similitud que veo es un desarrollo de la medicina muy basado en la especialidad y un incipiente desarrollo de la medicina general. Y lo que hay en la mayoría de los países, yo diría casi en todos, es una medicina indigena tradicional. Mucha gente la utiliza y sus relaciones con el sistema formal u oficial no están siempre muy claras: en Ecuador, en Bolivia, en Perú, en Brasil, pero en Chile también.

\section{REFORMA DE SALUD}

- Le correspondió un período de alta transformación del sistema de salud chileno ¿Cómo evalúa ese proceso?

- Es un período de cambios. Chile ha sido valiente al empezar una reforma. Lo más sencillo era continuar lo que se venía haciendo. $\mathrm{Y}$ era necesario por diferentes factores como el crecimiento de la población pero también por el desarrollo económico que hace que la gente pida más. Por otro lado, hay mas presión para comprar más medicamentos, más aparatos; los precios y los costos suben rápidamente y ningún país puede hacer frente a eso. Entonces, creo que era necesario y ahora que ya está decidido, hay que hacerlo andar. Ya no es el momento de preguntarse si es el mejor esquema, porque ése es el sistema que hay. El tiempo de la discusión ya pasó y ahora es mas bien el momento de poner en práctica la Reforma.

\section{- ¿Pero cómo evalúa el debate público en torno a la Reforma? ¿Fue suficiente?}

- Creo que en eso hay un dilema. Uno puede pensar que más discusión hubiese sido mejor pero como se había escogido la vía parlamentaria, que me parecía una buena vía entonces, había que ir cerrando el proceso y las discusiones tenían que darse en el Parlamento que era el camino escogido. En ese sentido funcionó, porque salió en el tiempo. Ahora, es cierto que en el sistema político chileno todavía hay mucha desconexión entre la política formal y los espacios más ciudadanos. Al escoger la vía parlamentaria, por lo tanto, se corría ese riesgo. El Parlamento no parece que juegue todavía el papel de reflejar todas las opiniones pero, por otro lado, si no se utiliza, nunca se va a lograr; por lo menos, hay un mecanismo constitucional que está establecido, que está claro y transparente cómo funciona. Ahora, uno ve que hay un poco de frustración en varios grupos por no haber podido intervenir más en el proceso de discusióm. Me imagino que en la puesta en práctica, habrá que hacerlo, si no, no va a funcionar. Si la gente no está convencida, va a ser muy complicado que resulte.

- Por la experiencia que tiene de cómo se gestó la reforma, ¿Cuáles cree que pueden ser los puntos más críticos en su aplicación?

- Veo dos. Uno es el hecho que se ha separado la Salud Pública y la prestación de servicios. Tiene su ventaja porque lo que es salud pública aparece claramente. El peligro radica en que se piense que la gestión de la red no sea un problema de Salud Pública $y$, entonces, empiece a funcionar de una manera totalmente autónoma, en una lógica de rentabilidad económica. Sin duda que tiene que tener otros límites, los establecimientos, los hospitales, la atención curativa en general es parte de la Salud Pública. En la práctica, se debe ver cómo se mantiene la conexión entre las dos porque si no, parecerá que son antagónicas, lo que resultaría muy complicado. El otro punto es el Plan Auge, se ha escogido 
una vía de definir patologías, como un tipo de canasta ampliada pero es complicada la parte técnica de definir completamente todos los protocolos, entonces, yo creo que necesita un proceso de simplificación para que la gente pueda entenderlo. Es complicado entender todas la sutilezas que están en el plan.

\section{DESARROLLO DE LA SALUD PÚBLICA}

\section{- ¿Cómo fue su experiencia de trabajo con la} Escuela de Salud Pública?

- Muy positiva. Yo veo que se están renovando los equipos, elevando el nivel académico, hay cada vez más doctorados, se ve un proceso de acumulación para el futuro. Las limitaciones son las que tiene todo el mundo académico en Latinoamérica; entre la docencia que ocupa mucho tiempo y que es importante y la necesidad de obtener financiamiento haciendo consultorías, queda muy poco espacio para la investigación. Entonces, una institución académica que no hace investigación, lo único que hace es transmitir conocimiento, no generarlo. El reto es impulsar la investigación para que alimente tanto la docencia como la capacidad de consultoría. También, mi impresión es que persiste, incluso mas allá de la Escuela de Salud Pública, de todo el mundo académico en general de América Latina un subfinanciamiento, que impide que el profesor titular tenga asistentes que le permitan realizar tanto investigación como docencia.

- ¿Cómo evalúa el desarrollo de la Salud Pública en Chile, comparativamente con otros países de Latinoamérica?

- Chile siempre ha tenido una tradición muy fuerte de salud pública y la sigue teniendo. Ahora, como todo en la vida, para continuar siendo líderes hay que renovarse, sino uno empieza a responder a problemas del pasado y no a problemas del futuro. Hay que ir pensando una salud pública que logre integrar a todos los actores del sector salud y no solamente los estatales. Creo que hay que lograr que los prestadores privados actúen en una lógica de salud pública y no en una lógica de mercado.
-Pero la experiencia chilena en áreas como la educación es que una vez que entran los privados con fuerza al negocio, la eficiencia y eficacia en el cumplimiento de los objetivos de la educación pública se deterioran. ¿Qué impediría que eso ocurra en el área de la salud?

- Es parecido a la educación. Si se deja todo al mercado, obviamente, el sistema va a funcionar en términos de mercado; no hay que esperar funcione en otro sentido. Pero, de todas maneras, es el Estado el último garante de los derechos del ciudadano.

\section{- ¿Y cómo ve esa tensión en Chile?}

- Estamos en ese momento de decisión, de definición, porque si se va solamente por el lado del mercado, me temo que los grandes logros que Chile siempre ha conseguido en salud pública, se puedan perder al irrumpir poblaciones nuevas que son las que presentan nuevas necesidades.

- ¿Pero todavía ve un margen de decisión?, si las nuevas leyes están aprobadas casi en su totalidad.

Sí, yo creo que sí. Depende de cómo los actores reaccionen. En general, me ha tocado observar la posición del mundo médico $y$, en general, reivindica una lógica de salud pública, la que tuvo bastante contraste con lo que primó tanto en el Parlamento como en el Gobierno, donde existía una visión mucho más dispuesta a abrirse al mercado. Ahora, cuando yo hablo de los actores, éstos no son solamente los médicos; hay un desafio para la gente que utiliza los servicios, en los aspectos que la ley no avanzó, la gente podría ser un instrumento importante.

\section{PASO POR CHILE}

- ¿Cómo podría resumir el rol de un Consultor de la OPS?

- Se trata de acompañar los procesos. Los procesos los determinan los propios países, no las agencias de fuera, pero una persona externa puede ver cosas que la gente del lugar no ve o no puede ver, o las ve y no puede decirlas. Puede aportar conocimiento, también, de lo 
que ha visto en otros países y puede ayudar a facilitar nexos con el resto del mundo. Entonces, básicamente, es un papel enzimático, de facilitar cosas pero no reemplazar.

\section{- Su presencia en Chile, ¿crees que logró jugar ese logro enzimático?}

- En algunas cosas, sí. En la reforma, un poco menos, porque se trataba de un tema complejo. En ayudar a que se tome más conciencia de la enfermedades emergentes, de la salud indigena, acompañar los procesos en torno al Sida; facilitando el diálogo entre el Ministerio y la sociedad civil. Ese rol facilitador muchas veces hace la diferencia.

\section{- El 2004, se dio a conocer la Encuesta} Nacional de Salud que reveló una serie de problemas como la obesidad, el sedentarismo, la hipertensión y, por supuesto, el tabaquismo ¿Hubo errores en la estrategia preventiva?

- Esos, precisamente, son los desafíos que están empezando. Justamente, es el momento de tomar decisiones. Hace un rato decía que los grandes adelantos que ha tenido Chile en Salud Pública podrían verse mermados, si no se logra entrar en estos nuevos cambios. En general, la reforma no aborda específicamente con la profundidad que se requiere estos temas. Lo que sí, identifica un componente de salud pública; uno puede pensar que desde ahí se podría dar más seguimiento y más énfasis sobre estos temas. Ojalá no se quede sólo en la institucionalidad y pasen cosas concretas. El desafío, también, es trabajar intersectorialmente, porque desde el ministro de Salud es difícil cambiar el sedentarismo o abordar la salud sexual. Todo esto está pendiente como estrategia intersectorial que permite abordarlo.

He pensado que esto se debe trabajar "desde abajo", es decir, desde los espacios naturales intersectoriales que son las comunas, los barrios, porque allí la vida también es intersectorial. Entonces, no son sólo políticas que bajan, sino que en las comunidades concretas debe existir la posibilidad de discutir y tomar la decisión sobre el estilo de vida que uno tiene.
- La política de salud pública ¿Cómo podría facilitar ese tipo de procesos?

- Eso depende de un funcionamiento del Estado en general, una política de vida democrática en la base. En general, este tema de la democratización estuvo muy presente en la discusión durante el 2004. Chile tiene un déficit de los 90 para acá, obviamente, se justifica por los años anteriores, pero de los 90 hacia acá hay un déficit democrático en una cantidad de elementos tanto de base como de proyectos ciudadanos.

- ¿Esa democratización aún está en pañales?

- Me parece que hay mucho miedo. Me parece que se podría avanzar mas rápidamente. Debe haber motivos para que no ocurra pero creo que los temores no tienen fundamento. No hay nada que temer a tener una vida democrática. Eventualmente, se pierde algo de control pero se gana mucho en implementación de políticas.

- ¿Cree que es posible proyectar una política de salud pública que no se haga cargo de esta dimensión?

Se puede pero tiene menos alcance, menos efectividad. Me parece que hay que vencer el temor a perder el control sobre algunos procesos.

\section{- A la luz de esta deuda ¿Con qué impresión deja Chile?}

- Se siente que hay un desarrollo muy importante en muchos aspectos pero falta más la posibilidad de discutir sin entrar en oposición violenta, es en el debate donde uno busca saber qué pasa y construir compromisos. Muchas veces, la gente sabe que se están tomando acuerdos pero no tiene acceso a ese debate, entonces, deja de creer. Hay una necesidad de aumentar la participación y tener debates más abiertos.

- Tuvo la oportunidad de compartir con mucha gente. Si alguien le pregunta, ¿Cómo son los chilenos?

- Son estupendos, es más a propósito de lo que hemos conversado sobre cómo funciona la sociedad chilena, los chilenos son bien concientes de ello, son los primeros en saber y 
si no avanza, es porque las cosas tienen que ir madurando, hay que ir rompiendo barreras $y$ será necesario si el país quiere desarrollarse. Porque el momento actual, supone una calidad de vida social grande.

\section{- ¿Deja amigos acá?}

- Más por el lado personal que por el trabajo, ambos se han ido mezclando también. En el caso de la Escuela de Salud Pública, también hay buenos amigos, espero volver a tener contacto con Oscar Arteaga, Paulina Pino, con el mismo Giorgio Solimano, María Teresa Valenzuela, Marcos Vergara y varios otros con que pude intercambiar.

\section{- Ahora vuelve a Bolivia ¿Cómo enfrenta este viejo-nuevo desafío?}

- De partida, es un país mucho más pobre que Chile. Obviamente, con una institucionalidad no tan desarrollada como la de acá. Entonces, cosas que aquí parecen obvias como tener acceso a los servicios y tener garantizada una atención básica, en Bolivia no existen. Se trata de implementar cosas que en Chile ya están superadas, como reducir la mortalidad infantil que todavía es muy alta, ampliar las coberturas y el acceso.

\section{- ¿Espera encontrar algo muy distinto a lo que dejó en 1999?}

- No, va a se bastante similar. Aunque sí, la problemática indígena ha tomado una dimensión mayor.

\section{- El asunto indígena parece ser importante en su reflexión...}

- Claro, como yo nací fuera de mi cultura, siempre he sido más sensible a las diferencias de cultura, porque siendo belga, el país donde he estado menos es en Bélgica.

\section{- Unas últimas palabras sobre su experiencia de trabajo en Chile...}

- Para mi ha sido un agrado estar aquí, un desafío profesional porque se trata de un ambiente profesionalmente exigente. Me ha permitido crecer al contacto de los profesionales chilenos, el intercambio y la experiencia chilena lo obliga a uno a estar más creativo y estudioso. Eso ha sido un gran aporte para mí, y lo agradezco mucho, además del cariño que siempre me han expresado. 